О.К. Фурсенко, Н.М. Черновол

Харківський національний університет Повітряних Сил ім. І. Кожедуба, Харків

\title{
ЛАНЧЕСТЕРОВСЬКІ МОДЕЛІ БОЙОВИХ ДІЙ
}

\begin{abstract}
Пропонується матеріал для викладання у вищих військових навчальних закладах з предмету “Вища математика" в розділі “Диференціальні рівняння” та з предмету “Прикладна математика”в розділах “Операційне числення" та “Теорія ймовірностей”. Розглянуто шість моделей Ланчестера у вигляді системи двох або трьох диференціальних рівнянь, щуо описують середні чисельності двох угрупувань в прочесі бою. До кожної з моделей наведено приклади, розв'язок яких дає можливість зробити прогноз: перемогою якого із угрупувань і через який час закінчиться бій $і$ які будуть втрати угрупування, щзо переможе. Крім того, до однієї з моделей розглянуто інший підхід, який теж дає можливість зробити прогноз бою.
\end{abstract}

Ключові слова: рівняння Ланчестера, рівняння динаміки бою, система диференціальних рівнянь, ефективна скорострільність,бойова одиниия.

\section{Вступ}

Постановка проблеми. В умовах бурхливого розвитку комп'ютерних та інформаційних технологій в сучасних умовах важливою є роль математичних компетенцій як частини професійних компетенцій фахівців різного профілю, в тому числі і майбутніх офіцерів. При цьому слід зазначати зростання ролі математики не тільки як мови точних наук, а отже i мови військово-технічних і військовоспеціальних дисциплін, а і іï безпосереднє використання для оцінювання ефективності нових видів зброї, прогнозування наслідків бою, моделювання нових технологій організації і ведення бойових дій.

Серед ієрархії математичних моделей бойових дій важливе місце належить ланчерестерівським моделям [1-2]. Вони пройшли більш як сторічну історію розвитку і життя показало їх ефективність. Велике різноманіття цих моделей різного рівня складності потребує їх аналізу, систематизації з метою введення в навчальний процес вищих військових навчальних закладів (ВВНЗ) в курси вищої i прикладної математики.

При цьому необхідно в умовах обмеженості часу, що виділяється для вивчення математики майбутніми офіцерами, органічно вписати даний матеріал в програми навчальних дисциплін і при цьому зберегти основне раціональне зерно в моделях, що пропонуються. Це підкреслить значення для курсантів вивчення математичних дисциплін і підготує їх до засвоєння і використання в майбутній професійній діяльності сучасних методів моделювання бойових дій.

Аналіз останніх досліджень і публікацій. Питаннями професійно орієнтованого викладання вищої математики в вищих навчальних закладах займались, наприклад, в роботах [3-6]. Але що стосується професійно орієнтованого викладання математичних дисциплін в ВВН3, то питання залишається не достатньо вивченим. Відома спроба вказати на задачі на базі рівнянь Ланчестера, які можна використати при проведенні практичних занять 3 теми “Диференціальні рівняння” в ВВНЗ в роботі [7]. В останній час моделям типа Ланчестера присвячено багато робіт, наприклад, [8-17]. Тому можна більш докладно вивчити питання введення в курс не тільки вищої математики а і прикладної математики в ВВНЗ моделей Ланчестера.

Мета статті - проаналізувати відомі в літературі ланчестеревські моделі і запропонувати доступні моделі для засвоєння курсантами ВВНЗ в програмах вищої і прикладної математики.

\section{Виклад основного матеріалу}

\section{1. Моделі динаміки бою для викладання з предмету "Вища математика" в розділі "Диференціальні рівняння"}

Розглянемо спочатку найпростішу модель Ланчестера, що докладно розглянута в [1]. Ця модель названа автором як модель А або модель “високоорганізованого бою”. Згідно цієї моделі бій проводиться при наступних умовах:

1. В бою беруть участь два угрупування: сторона 1 і сторона 2. У складі сторони $1-N_{1}$ однорідних бойових одиниць (наприклад, танків, кораблів, літаків, ракетних установок). У складі сторони 2 $N_{2}$ однорідних бойових одиниць, не обов'язково однорідних з бойовими одиницями сторони 2;

2. Кожна бойова одиниця сторін проводить випадковий потік пострілів по цілі зі середньою скорострільністю (для сторони $1-\lambda_{1}$, для сторони 
$\left.2-\lambda_{2}\right)$, потік пострілів є пуассонівським. (Середньою скорострільністю бойової одиниці називають середню кількість пострілів в одиницю часу);

3. Ймовірність влучення при кожному пострілі дорівнює для сторони $1-p_{1}$, для сторони $2-p_{2}$;

4. Одним пострілом можна знешкодити не більш ніж одну бойову одиницю;

5. Якщо бойова одиниця знешкоджена, вогонь миттєво переноситься на іншу, а сама уражена одиниця в подальших бойових діях не бере участі.

6. В будь-який момент часу сумарна бойова міць кожного угрупування пропорційна не самому випадковому числу бойових одиниць, що збереглися неушкодженими, а його середньому значенню (це припущення особливо природно для багаточисельних угрупувань).

Зауважимо, що бій називається високоорганізованим завдяки умові 5 .

Позначимо $y_{1}(t)$ - середнє число бойових одиниць сторони 1, які є неураженими в момент часу $t, y_{2}(t)-$ середне число бойових одиниць сторони 2 , які $\epsilon$ неураженими в момент часу $t$. Назвемо $y_{1}(t)$ i $y_{2}(t)$ середніми чисельностями сторін в момент часу $t$.

Введемо числа $\alpha_{1}=\lambda_{1} p_{1}, \alpha_{2}=\lambda_{2} p_{2}$.

Якщо $\lambda_{i}(i=1,2)-$ середня скорострільність бойової одиниці, то $\alpha_{i}(i=1,2)$ - середня ефективна скорострільність цієї одиниці (середня кількість успішних пострілів в одиницю часу).

Тоді система диференціальних рівнянь, що описує середню чисельність сторін 1 і 2 в процесі бою має вигляд (див. [1]):

$$
\left\{\begin{array}{l}
y_{1}^{\prime}=-\alpha_{2} y_{2} . \\
y_{2}^{\prime}=-\alpha_{1} y_{1} .
\end{array}\right.
$$

Початкові умови: $y_{1}(0)=N_{1}, \quad y_{2}(0)=N_{2}$.

Розв'язується система (1) методом виключення. Можна проаналізувати з курсантами “високоорганізований бій” на наступному прикладі.

Приклад 1. Відбувається бій між двома угрупуваннями: 50 батарей сторони 1 ведуть контрбатарейну боротьбу з 25 батареями сторони 2. Батареї сторони 1 мають середню скорострільність 0,25 пострілів в хвилину, ймовірність влучення при кожному пострілі 0,64. Батареї сторони 2 мають скорострільність 0,5 пострілів в хвилину, ймовірність влучення при кожному пострілі 0,5. Зробити прогноз розвитку бою: вказати, перемогою якої із сторін і через який час закінчиться бій і які будуть приблизно втрати сторони-переможниці.

Розв'язання.

Маємо: $\quad N_{1}=50, \quad \lambda_{1}=0,25, \quad p_{1}=0,64$; $N_{2}=25, \lambda_{2}=0,5, \quad p_{2}=0,5$.
Система диференціальних рівнянь, що описує середню чисельність сторін 1 і 2 в процесі бою має вигляд (1). Початкові умови: $y_{1}(0)=50, \quad y_{2}(0)=25$.

Обчислимо $\alpha_{1}=\lambda_{1} p_{1}=0,16, \alpha_{2}=\lambda_{2} p_{2}=0,25$. Підставимо в систему (1):

$$
\left\{\begin{array}{l}
y_{1}^{\prime}=-0,25 y_{2} \\
y_{2}^{\prime}=-0,16 y_{1}
\end{array}\right.
$$

Розв'яжемо методом виключення. 3 першого рівняння знайдемо $y_{2}: y_{2}=-4 y_{1}^{\prime}$. Обчислимо: $y_{2}^{\prime}=-4 y_{1}^{\prime \prime}$. Підставимо у друге рівняння отриманої системи:

$$
-4 y_{1}^{\prime \prime}=-0,16 y_{1} \Leftrightarrow y_{1}^{\prime \prime}-0,04 y_{1}=0 \text {. Останнє рі- }
$$
вняння $\epsilon$ лінійним однорідним диференціальним рівнянням другого порядку зі сталими коефіцієнтами. Розв'язання таке.

Характеристичне рівняння $\mathrm{i}$ його корені: $\lambda^{2}-0,04=0, \quad \lambda_{1,2}= \pm 0,2$. Загальний розв'язок:

$y_{1}(t)=C_{1} e^{0,2 t}+C_{2} e^{-0,2 t}$. Знайдемо похідну від $y_{1}(t): y_{1}^{\prime}(t)=0,2 C_{1} e^{0.2 t}-0,2 C_{2} e^{-0,2 t}$. Тоді: $y_{2}(t)=-4 y_{1}^{\prime}(t)=-0,8 C_{1} e^{0,2 t}+0,8 C_{2} e^{-0,2 t}$.

Отже розв'язок системи: $\left\{\begin{array}{c}y_{1}(t)=C_{1} e^{0,2 t}+C_{2} e^{-0,2 t} \\ y_{2}(t)=-0,8 C_{1} e^{0,2 t}+0,8 C_{2} e^{-0,2 t}\end{array}\right.$

Враховуючи початкові умови, маємо систему для знаходження $C_{1}, C_{2}:\left\{\begin{array}{c}C_{1}+C_{2}=50 \\ -0,8 C_{1}+0,8 C_{2}=25 .\end{array}\right.$ Отриму€MO:

$C_{1}=9,375, C_{2}=40,625$. Таким чином, чисельності сторін 1 і 2 в процесі бою в момент часу: $\left\{\begin{array}{c}y_{1}(t)=9,375 e^{0,2 t}+40,625 e^{-0,2 t} \\ y_{2}(t)=-7,5 e^{0,2 t}+32,5 e^{-0,2 t}\end{array}\right.$ Оскільки $y_{1}(t) \neq 0$ $\begin{array}{llll}\text { нi } & \text { при } & \text { яких }\end{array}$ сторона 1 переможе.

Розв'яжемо: $y_{2}(t)=0 ; 7,5 e^{0,2 t}=32,5 e^{-0,2 t} ; t \approx 3,66$.

Таким чином, бій закінчиться приблизно через 3 хвилини 40 секунд. Обчисливши $y_{1}(3,66) \approx 39,03$, отримуємо, що втрати сторони 1 - приблизно 11 батарей.

Наступною простою моделлю динаміки бою є модель В або модель “поганоорганізованого бою”, яка розглянута в [1-2].

При виведенні рівнянь Ланчестера моделі А припускалось, що інформація про враження цілі поступає миттєво, як тільки бойова одиниця противника знищена, бойова одиниця, що вразила цю ціль одразу переносить вогонь на іншу ціль (тобто по 
враженим бойовим одиницям не стріляють). Розглянемо бій, при якому інформація про враження цілі відсутня і переніс вогню не відбувається.

Розглянемо постановку задачі моделі А, де замість умови 5 виконується Умова

5'. Інформація про враження цілі відсутня і переніс вогню не відбувається.

Система диференціальних рівнянь, що описує середню чисельність сторін 1 і 2 в процесі бою має вигляд:

$$
\left\{\begin{array}{l}
y_{1}^{\prime}=-\frac{\alpha_{2}}{N_{1}} y_{2} y_{1} \\
y_{2}^{\prime}=-\frac{\alpha_{1}}{N_{2}} y_{1} y_{2} .
\end{array}\right.
$$

Для розгляду цієї моделі можна запропонувати розв'язати наступний приклад.

Приклад 2. Сторона 1 робить напад на сторону 2 за допомогою 16 літаків. Сторона 2 веде оборону за допомогою 8 систем ППО. Кожен літак сторони 1 робить в середньому 8 прицільних пострілів в хвилину, а система ППО сторони 2 робить в середньому 10 пострілів в хвилину. Ймовірність влучення при кожному пострілі сторони 1 дорівнює 0,2, а ймовірність влучення при кожному пострілі сторони 2 дорівнює 0,4. Визначити результати бою через 5 хвилин.

Узагальненням моделі А є модель С, що висвітлюється в [1]. Назвемо цю модель як “високоорганізований бій $з$ поповненням".

Постановка задачі така, як для моделі А, але є ще одна умова (крім 1-6):

7. Кожна сторона за одиницю часу поповнюється бойовими одиницями (сторона $1-n_{1}(t)$ одиницями, сторона $2-n_{2}(t)$ одиницями).

Як пояснено в [1], система диференціальних рівнянь, що описує середню чисельність сторін 1 і 2 в процесі бою:

$$
\left\{\begin{array}{l}
y_{1}^{\prime}=-\alpha_{2} y_{2}+n_{1}(t) \\
y_{2}^{\prime}=-\alpha_{1} y_{1}+n_{2}(t) .
\end{array}\right.
$$

Розв'язується ця система методом виключення.

Запропонуємо наступний приклад.

Приклад 3. Відбувається високоорганізований бій $з$ поповненням між двома угрупуваннями: сторона 1 у складі 20 бойових одиниць і сторона 2 у складі 24 одиниць. Бойові одиниці сторони 1 мають середню скорострільність 8 пострілів за годину, ймовірність влучення при кожному пострілі 0,5, поповнюються 2 одиницями за годину. Бойові одиниці сторони 2 мають середню скорострільність 2,5 пострілів за годину, ймовірність влучення при кожному пострілі 0,4, поповнюються 4 одиницями. 3робити прогноз розвитку бою: вказати, перемогою якої iз сторін і через який час закінчиться бій і скільки приблизно неуражених бойових одиниць залишиться у сторони-переможниці.

Зауваження 1: при виводі рівнянь моделей А, В і C припускали, що постріл, направлений по одній із бойових одиниць, може знешкодити тільки цю бойову одиницю і не може знешкодити інші. Таке припущення вірне тільки для снарядів малої потужності або для розсереджених цілей. Тобто снаряд може мати радіус дії (може знешкоджувати декілька бойових одиниць). Додамо до умов, наприклад моделі $\mathrm{A}$, що бойові одиниці мають деякий радіус дії: нехай $k_{1}-$ середнє число сусідніх (додаткових) одиниць, що знешкоджуються бойовою одиницею сторони 1 за постріл, $k_{2}$ - середнє число сусідніх (додаткових) одиниць, що знешкоджуються бойовою одиницею сторони 2 за постріл. Тоді система диференціальних рівнянь, що описує середню чисельність сторін 1 i 2 в процесі такого бою має вигляд [1]:

$$
\left\{\begin{array}{l}
y_{1}^{\prime}=-\alpha_{2} y_{2}-\frac{\alpha_{2} k_{1}}{N_{1}} y_{2} y_{1} \\
y_{2}^{\prime}=-\alpha_{1} y_{1}-\frac{\alpha_{1} k_{2}}{N_{2}} y_{1} y_{2} .
\end{array}\right.
$$

Тобто, чим більше враховується факторів, що впливають на бій, тим складніші рівняння.

За допомогою рівнянь динаміки бою можна врахувати і інші фактори, як попереджуючий удар однієї сторони, темп мобілізації сил, закінчення боєприпасів на деякий час і їх відновлення і т.д. В цьому випадку $\alpha_{1}$ i $\alpha_{2}$ будуть змінюватися по деякому закону: $\alpha_{1}=\alpha_{1}(t), \alpha_{2}=\alpha_{2}(t)$.

Зауваження 2: розглянемо модель $\mathrm{C}$ i нехай бій затяжний і відомий коефіцієнт, що вказує на інтенсивність втрат бойових одиниць внаслідок хвороб за одиницю часу ( $\beta_{1}-$ для сторони $1, \beta_{2}-$ для сторони 2). Тоді система для опису середніх чисельностей обох сторін буде мати вигляд [7]:

$$
\left\{\begin{array}{c}
y_{1}^{\prime}=-\alpha_{2} y_{2}-\beta_{1} y_{1}+n_{1}(t) \\
y_{2}^{\prime}=-\alpha_{1} y_{1}-\beta_{2} y_{2}+n_{2}(t) .
\end{array}\right.
$$

Таку задачу теж можна розглянути в курсі вищої математики.

Наступною моделлю, яку можна запропонувати курсантам, є модель D. Вона розглянута, наприклад, в [8-9]. Назвемо іiі моделлю “мішаного бою”.

Розглянемо припущення задачі моделі А, де замість умови 5 інша умова:

5/. якщо бойова одиниця знешкоджена стороною 2, то вогонь переноситься на іншу одиницю. Для сторони 1 інформація про враження цілі відсутня і переніс вогню не відбувається.

Скориставшись рівнянням в моделі А для $y_{1}$ i рівнянням в моделі В для $y_{2}$, отримаємо наступну 
систему, що описує середню чисельність сторін 1 і 2 в процесі бою:

$$
\left\{\begin{array}{c}
y_{1}^{\prime}=-\alpha_{2} y_{2} \\
y_{2}^{\prime}=-\frac{\alpha_{1}}{N_{2}} y_{1} y_{2}
\end{array}\right.
$$

Цю систему теж неважко розв’язати. Тому пропонуємо наступний приклад.

Приклад 4. Нехай відбувається мішаний бій між двома угрупуваннями танків. Для сторони 1: $N_{1}=30, \quad \lambda_{1}=10 \frac{\text { nостр }}{\text { годину }}, \quad p_{1}=0,4$, . Для сторони 2 : $N_{2}=40, \lambda_{2}=4 \frac{\text { постр }}{\text { годину }}, p_{2}=0,5$. Зробити прогноз розвитку бою.

Також в розділі “Диференціальні рівняння" можна розглянути модель А 3 іншим аналізом, як запропоновано в [10]. Автором [10] вводиться показник $K(t)=\frac{y_{1}(t)}{y_{2}(t)}$, що характеризує співвідношення сил сторін в процесі бою. Диференціюючи $K(t), \mathrm{i}$ користуючись рівняннями системи (1), отримується диференціальне рівняння, що є рівнянням Ріккаті для показника $K(t)$ :

$$
K^{\prime}=\alpha_{1} K^{2}-\alpha_{2}
$$

Початкова умова: $K(0)=\frac{N_{1}}{N_{2}}$. Ввівши заміну $U=\frac{1}{K-\sqrt{\frac{\alpha_{2}}{\alpha_{1}}}}$, рівняння (5) зводиться до рівняння, що $\epsilon$ рівнянням 3 відокремлюваними змінними: $U^{\prime}=-2 \sqrt{\alpha_{1} \alpha_{2}} U-\alpha_{1}$.

Розв'язавши це рівняння 3 початковою умовою $U(0)=\frac{1}{K(0)-\sqrt{\frac{\alpha_{2}}{\alpha_{1}}}}, \quad$ знайдемо $U(t), \quad$ а потім $K(t)=\frac{1}{U(t)}+\sqrt{\frac{\alpha_{2}}{\alpha_{1}}}$. Відмінність такого розгляду полягає в тому, що не знаходячи чисельності $y_{1}(t), y_{2}(t)$, можна зробити прогноз бою. Якщо $K(0)<\sqrt{\frac{\alpha_{2}}{\alpha_{1}}}$, показник співвідношення сил $K(t)$ спадає і якщо $K(t)=0$, то переможе сторона 2. Розв'язавши рівняння $K(t)=0$, знаходимо час продовження бою. При $K(0)>\sqrt{\frac{\alpha_{2}}{\alpha_{1}}}$ функція $K(t)$ зростає і якщо $K(t) \rightarrow+\infty$ при $t \rightarrow t_{0}$, то переможе сторона 1. Відповідно час продовження бою дорів- нює $t_{0}$. Зауважимо, що в будь-який допустимий момент часу $t$, що відповідає нерівності $K(t) \geq 0$, можна знайти перевагу однієї сторони над іншою.

Пропонується розглянути приклад 1 i, знайшовши параметр $K(t)$, зробити прогноз бою: яка сторона переможе і через який час.

Розв'язання.

Маємо $\alpha_{1}=0,16, \alpha_{2}=0,25$. Тоді рівняння (5) буде мати вигляд $K^{\prime}=0,16 K^{2}-0,25$.

Початкова умова: $K(0)=2$. Зробимо заміну $U=\frac{1}{K-\sqrt{\frac{\alpha_{2}}{\alpha_{1}}}}=\frac{1}{K-\frac{5}{4}}$. Тоді $K=\frac{1}{U}+\frac{5}{4}$. Отримуємо рівняння: $U^{\prime}=-0,4 U-0,16$. Це рівняння $€$ рівнянням з відокремлюваними змінними.

Розв'язання таке:

$\frac{d U}{d t}=-0,4 U-0,16, \frac{d U}{U+0,4}=-0,4 t$,

$\ln |U+0,4|=-0,4 t+C_{1}, U=C e^{-0,4 t}-0,4$. Враховуючи початкову умову $U(0)=\frac{1}{K(0)-\frac{5}{4}}=\frac{4}{3}$, маємо: $\frac{4}{3}=C-0,4 ; C=\frac{26}{25}$. Отже, $U(t)=\frac{26}{15} e^{-0,4 t}-0,4$.

Тому показник співвідношення сил сторін: $K(t)=\frac{1}{\frac{26}{15} e^{-0,4 t}-0,4}+\frac{5}{4}=\frac{\frac{13}{6} e^{-0,4 t}+0,5}{\frac{26}{15} e^{-0,4 t}-0,4} . \quad$ Знаменик останнього дробу прямує до нуля при $t \rightarrow t_{0}=2,5 \ln \frac{13}{3} \approx 3,66$. Отже, при $t \rightarrow t_{0}$, $K(t) \rightarrow+\infty$. Звідси випливає, що приблизно через 3 хвилини 40 секунд сторона 1 переможе.

Зауважимо, що отримали той самий результат, але цей спосіб не дає змоги вказати, скільки неушкоджених одиниць залишиться у сторони 1.

\section{2. Модель динаміки бою для викладання 3 предмету “Прикладна математика" в розділі “Операційне числення"}

Розглянемо модель, що викладена в [11]. Нехай відбувається бій між двома угрупуваннями. Сторона 1 має в своєму складі $N_{1}$ бойових одиниць і $N_{2}$ бойових одиниць, різнорідних $3 N_{1}$ одиницями. Сторона 2 має $N_{3}$ бойові одиниці. Будемо дотримуватись форми організації ведення бою, яка відповідає моделі бою А. Тоді середні чисельності $y_{1}(t), y_{2}(t)$ угрупувань сторони 1 і $y_{3}(t)$ сторони 2 описуються системою диференціальних рівнянь: 


$$
\left\{\begin{array}{c}
y_{1}^{\prime}=-\alpha_{3} \gamma_{31} y_{3} \\
y_{2}^{\prime}=-\alpha_{4} \gamma_{32} y_{3} \\
y_{3}^{\prime}=-\alpha_{1} y_{1}-\alpha_{2} y_{2},
\end{array}\right.
$$

де $\alpha_{1}, \alpha_{2}-$ середні ефективні скорострільності сторони $1, \alpha_{3}, \alpha_{4}-$ середні ефективні скорострільності сторони $2, \gamma_{31}, \gamma_{32}-$ коефіцієнти цілерозподілу (частка бойових одиниць сторони 2, які виділяються для ураження цілей із складу $N_{1}$ i $N_{2}$ сторони 13 урахуванням їх важливості на момент часу $t$ ). Початкові умови:

$$
y_{1}(0)=N_{1}, y_{2}(0)=N_{2}, y_{3}(0)=N_{3} .
$$

Розв'язок системи (6) знаходиться наступним чином. Застосувавши перетворення Лапласа до системи (6), отримаємо систему трьох алгебраїчних рівнянь відносно зображень $Y_{1}(p), Y_{2}(p), Y_{3}(p)$ середніх чисельностей:

$$
\left\{\begin{array}{c}
p Y_{1}(p)-N_{1}=-\alpha_{3} \gamma_{31} Y_{3}(p) ; \\
p Y_{2}(p)-N_{2}=-\alpha_{4} \gamma_{32} Y_{3}(p) ; \\
p Y_{3}(p)-N_{3}=-\alpha_{1} Y_{1}(p)-\alpha_{2} Y_{2}(p) .
\end{array}\right.
$$

Розв'язавши отриману систему і перейшовши до оригіналів, отримаємо частинний розв'язок системи (6) при початкових умовах (7). По цьому розв'язку можна зробити прогноз бою. Для розгляду пропонуємо наступний приклад.

Приклад 5. Нехай відбувається бій між двома угрупуваннями: 20 танків і 30 артилеристів сторони 1 і 60 танків сторони 2. Крім того, для сторони 1: середня ефективна скорострільність танків - 8 пострілів за годину, для артилеристів - 6 пострілів за годину. Для сторони 2: середня ефективна скорострільність танків по танкам - 5 пострілів за годину, коефіцієнт цілерозподілу - 0,6; середня ефективна скорострільність танків по артилеристам - 5 пострілів за годину, коефіцієнт цілерозподілу - 0,4. Зробити прогноз розвитку бою: вказати, перемогою якої із сторін і через який час закінчиться бій і які будуть приблизно втрати сторони-переможниці.

\section{3. Модель динаміки бою для викладання з предмету “Прикладна математика" в розділі "Теорія ймовірностей"}

Розглянемо модель, що докладно описана в [12]. Бій проводиться між двома угрупуваннями при умовах 1,4,5',6 (див. формулювання умов для моделей A,B), а замість умов 2,3 розглядається наступна умова: кожна бойова одиниця сторін виконує пуасонівський потік уражаючих пострілів з відповідними інтенсивностями (сторона 2 по стороні 1 з інтенсивністю, що дорівнює $\lambda_{2} q_{2} r_{2}$, де $\lambda_{2}-$ середня скорострільність бойової одиниці сторони $2, q_{2}$ - ймовірність накриття цілі сторони 1 областю розривів, $r_{2}$ - умовна ймовірність ураження цілі за умови, що вона накрита зоною рівномірного розсіювання; сторона 1 по стороні 2 з інтенсивністю що дорівнює $\lambda_{1} q_{1} r_{1}$, де $\lambda_{1}, q_{1}, r_{1}$ визначаються відповідно аналогічно параметрам $\left.\lambda_{2}, q_{2}, r_{2}\right)$. В [12] побудована модель бою наступним чином. Розглянуто по два стани для кожної сторони, в яких може перебувати бойова одиниця: $S_{1}$ (відповідно $S_{2}$ ) - бойова одиниця сторони 1 (відповідно сторони 2) не уражена, $S_{3}$ (відповідно $S_{4}$ ) - бойова одиниця сторони 1 (відповідно сторони 2) уражена. Вважається, що в системі $S=\left(S_{1}, S_{2}, S_{3}, S_{4}\right)$ протікає марківський процес 3 дискретною множиною станів і неперервним часом. Позначимо $P_{i}(t)$ - ймовірність того, що в момент часу $t$ система $S$ знаходиться в стані $S_{i}(i=1,2,3,4)$. Процес переходу системи $S$ iз стану в стан зображується графом (рис. 1).
Сторона 1

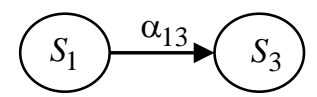

неуражена уражена
Сторона 2

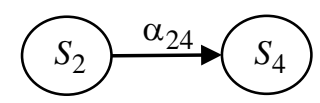

неуражена уражена
Рис. 1. Граф станів бойових одиниць сторін 1 і 2 Джерело: розроблено авторами.

Тут $\alpha_{13}$ (відповідно $\alpha_{24}$ ) - інтенсивності переходу системи із стану $S_{1}$ в стан $S_{3}$ (відповідно із стану $S_{2}$ в стан $S_{4}$ ). На основі графа отримуємо систему диференціальних рівнянь Колмогорова для ймовірностей $P_{1}(t)$ і $P_{2}(t)$ станів $S_{1}$ і $S_{2}$ відповідно:

$$
\left\{\begin{array}{c}
P_{1}^{\prime}=-\alpha_{13} P_{1} \\
P_{2}^{\prime}=-\alpha_{24} P_{2} .
\end{array}\right.
$$

Виходячи з умов бою параметри $\alpha_{13}$ i $\alpha_{24}$ дорівнюють:

$$
\alpha_{13}=\lambda_{2} q_{2} r_{2}, \alpha_{24}=\lambda_{1} q_{1} r_{1} .
$$

Підставивши (9) в (8) і скориставшись принципом квазірегулярності, отримаємо систему диференціальних рівнянь, що описує середні чисельності $y_{1}(t)$ і $y_{2}(t)$ бойових одиниць сторін 1 і 2 в момент чacy $t$ :

$$
\left\{\begin{array}{l}
y_{1}^{\prime}=-\frac{\lambda_{2} q_{2} r_{2}}{N_{1}} y_{1} y_{2} \\
y_{2}^{\prime}=-\frac{\lambda_{1} q_{1} r_{1}}{N_{2}} y_{1} y_{2} .
\end{array}\right.
$$

Для розгляду цієї моделі пропонується приклад.

Приклад 6. Відбувається бій між двома угрупуваннями: 20 бойових одиниць сторони 1 і 40 бойових одиниць сторони 2. Крім того, для сторони 1 : 
середня скорострільність - 4 постріли в хвилину, ймовірність накриття цілі областю розривів - 0,6, умовна ймовірність ураження цілі за умови, що вона накрита зоною рівномірного розсіювання - 0,2; для сторони 2: середня скорострільність - 2 постріли в хвилину, ймовірність накриття цілі областю розривів - 0,4, умовна ймовірність ураження цілі за умови, що вона накрита зоною рівномірного розсіювання $-0,2$. Визначити результати бою через 10 хвилин.

\section{Висновки}

Дуже важливим при викладанні вищої і прикладної математики в вищих військових навчальних за- кладах є питання розв'язання задач військової спрямованості. До розділів, де це питання можна вирішити, відносяться розділи: "Диференціальні рівняння", ”Операційне числення”, "Теорія ймовірностей”. В роботі запропоновано вводити в навчальний процес в розділи “Диференціальні рівняння”, ”Операційне числення”, "Теорія ймовірностей” вивчення моделей Ланчестера, які дають можливість робити прогноз військового протистояння. Вказане є важливим для мотивації вивчення вищої і прикладної математики, для покращення військової освіти майбутніх офіцеpiв.

\section{Список літератури} $388 \mathrm{c}$

1. Вентцель Е.С. Введение в исследование операций: монография / Е.С. Вентцель. - М.: Советское радио, 1964. -

2. Основы исследования операций в военной технике: монография / Ю.В. Чуев, П.М. Мельников, С.И. Петухов, Г.Ф. Степанов, Я.Б. Шор. - М.: Советское радио, 1965. - 592 с.

3. Козлакова Г.О. Науково-методична підтримка розвитку вищої природничо-математичної освіти в технічних університетах / Г.О. Козлакова, Т.В. Ковалюк // Розвиток інтелектуальних умінь і творчих здібностей учнів та студентів у процесі навчання математики: тези доповідей Всеукраїнської науково-методичної конференції. - Суми, 3-14 грудня 2009 p. - C. 208.

4. Хом’юк І.В. Про формування професійної спрямованості студентів технічних ВНЗ у процесі вивчення теорії ймовірностей / І.В. Хом’юк // Вісник Вінницького політехнічного університету. - 2004. - № 3. - С. 85-89.

5. Букатар М.I. 3 досвіду викладання вищої математики для студентів економічних спеціальностей / М.I. Букатар, I.I. Дрінь, В.П. Лавренчук // Методологія викладання математичних дисциплін для нематематичних спеціальностей у сучасних умовах: тези доповідей Всеукраїнської науково-методичної конференції. - Суми, 16-18 грудня 2009 р. - C. 39-41.

6. Бондаренко 3.В. Якісний аналіз розв'язків систем диференціальних рівнянь як засіб формування деяких компонентів професійної культури студентів / 3.В. Бондаренко // Вісник Вінницького політехнічного інституту. - 2004. - № 1. - C. $115-120$

7. Хитряк О. Деякі застосування диференціальних рівнянь в військовій справі / О. Хитряк, М. Сорокатий, О. Петрученко // Збірник наукових праць Національної академії державної прикордонної служби України. - 2016. - № 1(67). C. 319-330.

8. Пашков Н.Ю. Смешанная модель динамики средних для многочисленных группировок / Н.Ю. Пашков, В.П. Строгалев, В.Ю. Чуев // Оборонная техника. - 2010. - № 10(9). - С. 19-21.

9. Чуев В.Ю. “Смешанные” вероятностные модели двусторонних боевых действий многочисленных группировок / В.Ю. Чуев, И.В. Дубограй, Л.Н. Дьякова // Математическое моделирование и численные методы. - 2017. - № 1. C. 91-101. https://doi 10.18698/2309-3684-2017-1-91101.

10. Буравлев А.И. Дифференциальное уравнение для количественного соотношения численностей противоборствующих сил / А.И. Буравлев // Вооружение и экономика. - 2009. - № 4(8). - С. 4-8.

11. Узагальнення аналітичної моделі бою для різнорідних протидіючих угрупувань / В.І. Грабчак, В.М. Супрун, А.О. Вакал, П.М. Петренко // Збірник наукових праць Харківського університету Повітряних Сил ім. І. Кожедуба. 2008. - № 2(17). - С. 10-13.

12. Грабчак B.I. Аналітична модель бою між протидіючими угрупованнями / В.I. Грабчак, В.М. Супрун, А.М. Заскока // Військово-технічний збірник. - 2012. - № 1(6). - С. 110-120.

13. Чуєв В.Ю. Вероятностная модель боя многочисленных группировок / В.Ю. Чуєв // Вестник Московского государственного технического университета им. Н.Э. Баумана. - 2011. - № 2. - С. 223-232.

14. Машкін О.О. Особливості чисельного вирішення диференціальних рівнянь моделей ланчестерського типу у стохастичній постановці / О.О. Машкін // Система обробки інформації. - 2020. - № 1(160). - C. 67-72. https://doi 10.30748/soi:2020.160.08.

15. Новиков Д.А. Иерархические модели военных действий / Д.А. Новиков. - М.: НПУ им. В.А. Трапезникова PAH, 2012. $-62 \mathrm{c}$.

16. Чуев В.Ю. Стохастизм и детерминизм при моделировании двухсторонних боевых действий / В.Ю. Чуев, И.В. Дубограй // Весник Московского государственного технического университета им. Н.Э. Баумана. - 2017. - № 4. C. 16-28. https://doi 10.18698/1812-3368-2017-4-16-28.

17. Чуев В.Ю. Вероятностная модель дуэльного боя с переменными єффективными скорострельностями / В.Ю. Чуев, И.В. Дубограй // Весник Московского государственного технического университета им. Н.Э. Баумана. 2016. - № 3. - C. 118-124. https://doi 10.18698/0236-3941-2016-3-118-124. 


\section{Відомості про авторів:}

Фурсенко Олександр Кузьмич кандидат технічних наук доцент завідувач кафедри

Харківського національного університету Повітряних Сил ім. І. Кожедуба, Харків, Україна

https://orcid.org/0000-0002-8681-6742

\section{Черновол Наталія Миколаївна}

старший викладач

Харківського національного університету

Повітряних Сил ім. І. Кожедуба,

Харків, Україна

https://orcid.org/0000-0002-7988-7016

\section{Information about the authors:}

Oleksandr Fursenko

Candidate of Technical Sciences Associate Professor

Head of Department

of Ivan Kozhedub Kharkiv

National Air Force University,

Kharkiv, Ukraine

https://orcid.org/0000-0002-8681-6742

Nataliya Chernovol

Senior Instructor

of Ivan Kozhedub Kharkiv

National Air Force University,

Kharkiv, Ukraine

https://orcid.org/0000-0002-7988-7016

\title{
ЛАНЧЕСТЕРОВСКИЕ МОДЕЛИ БОЕВЫХ ДЕЙСТВИЙ
}

\author{
А.К. Фурсенко, Н.Н. Черновол
}

Предлагается материал для изложения в высших военных учебных заведениях по предмету "Высшая математика" в разделе “Дифференцильные уравнения" и предмету “Прикладная математика" в разделах "Операционное исчисление" и “Теория вероятностей”. Рассмотрено шесть моделей Ланчестера в виде системи двух или трех дифференциальных уравнений, которые описывают средние численности двух группировок в процессе боя. $K$ каждой из моделей приведен пример, решение которого дает возможность сделать прогноз: победой какой из группировок и через какое время закончится бой и какие будут потери группировки, которая победит. Кроме того, для одной из моделей рассмотрен другой подход, который так же дает возможность сделать прогноз боя.

Ключевые слова: уравнение Ланчестера, уравнение динамики боя, система дифференииальных уравнений, еффективная скорострельность, боевая единииа.

\section{LANCHESTER MODELS OF COMBAT OPERATIONS}

\section{O. Fursenko, N. Chernovol}

The material for presentation in higher military educational institutions on the discipline "Higher mathematics" in the section "Differential equations" and the discipline "Applied mathematics" in the sections "Operational calculus" and "Probability theory" is offered. Four Lanchester models are presented for study in the section "Differential equations". Namely, the conditions under which the battle takes place are formulated, the parameters of the battle are introduced, and a system of two differential equations is drawn up, which describes the average number of two groups in the process of battle. An example is provided for each model. The solution of the corresponding system makes it possible to provide a prediction of the battle: which faction will win and after what time the battle will end, and what will be the losses of the faction that will win. An example for the first model (model A) is given with the solution. In addition, a different approach to analyzing the progress of a battle using the parameter of the ratio of forces at any time is considered for Model A. Without solving the system, but solving only one differential equation of the first order, one can also analyze the battle: which group will win and after what time. An example is provided with a solution. Next, a model of combat dynamics is discussed for study in the Operational Calculus section. One of the groups consists of two disparate combat units. Therefore, the system consists of three differential equations. It is advisable to apply an operational method to its solution: apply the Laplace transform, obtain a system of three algebraic equations for images of average numbers, solve this system, go to the originals and thereby obtain a solution to the original system with initial conditions, and analyze the battle. An example is also given for this model. Finally, a combat dynamics model is proposed for consideration in the Probability Theory section. Based on the graph of states of combat units of two groupings, a system of two differential equations was obtained for the probabilities of states when a combat unit of the corresponding grouping is not destroyed. Further, based on the principle of quasi-regularity, a system of two differential equations was obtained for the average numbers of combat units of two groups at any time. An example is also given for this model. The study of these models is important for motivating the study of higher and applied mathematics, for improving the military education of future officers.

Keywords: Lanchester's equation, battle dynamics equation, system of differential equations, effective rate of fire, combat unit. 